\title{
Eine Ode an das D
}

_ Wann hat Sie ein Vortrag zum letzten Mal derart überzeugt, dass er Ihre Gewohnheiten nachhaltig beeinflusst hat? Mir ging das kürzlich so, als ich Prof. Dr. med. Jörg Spitz zum Thema Ernährung erlebte. „Laaaangweilig“, werden Sie jetzt vielleicht denken. Neu und beeindruckend war für mich dabei vor allem die Bedeutung von Vitamin D.

_ Oder wussten Sie, dass mit steigendem Vitamin-D-Spiegel das Risiko sinkt, an Krebs oder einer anderen Zivilisationskrankheit wie Herzinfarkt, Schlaganfall oder Diabetes zu erkranken? Fast alle Zellen benötigen dieses Hormon, um den Zellstoffwechsel zu steuern. Richtig gelesen. Vitamin D ist eigentlich ein Hormon, das der Körper mithilfe der Sonne selbst bildet. Eine spitzenmäßige körpereigene Präventionsmaßnahme sozusagen. Vorausgesetzt, der Körper bekommt überhaupt Sonne ab.

_ Trotz seiner immun- und muskelstärkenden Wirkung ist Vitamin D natürlich kein Allheilmittel. Und wie mit vielen Dingen gilt auch hier: Jeder braucht seine eigene clevere Lösung. Ob Sonne, Sonnenbank oder Pille - die richtige Dosis macht's. Wer Vitamin D am liebsten auf natürliche Weise bilden möchte, sollte darauf achten, dass er in der warmen Jahreszeit Sonne tankt. Die beste Voraussetzung ist dann gegeben, wenn der Körper einen kürzeren Schatten wirft, als die Körperlänge misst.

_ Mich jedenfalls hat Prof. Spitz derart beeindruckt, dass ich im Anschluss an seinen Vortrag in die nächste Apotheke gegangen bin, um mir für die restlichen Wintermonate eine Packung Vitamin D zu besorgen. Und auf meinen Mittagspausenspaziergang unter freiem Himmel lege ich neuerdings auch besonderen Wert. Der Frühling kann kommen.

\section{Sonnige Grüße}

Ihre

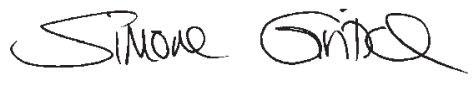

\begin{tabular}{|c|c|}
\hline \multicolumn{2}{|l|}{ ZU GEWINNEN } \\
\hline \multicolumn{2}{|l|}{ Kursplatz } \\
\hline \multicolumn{2}{|l|}{1 Kurs } \\
\hline „Frühkindlicher Autismus“ & Seite 53 \\
\hline \multicolumn{2}{|l|}{ Bücher } \\
\hline 3-mal „French Basics“ & Seite 45 \\
\hline \multicolumn{2}{|l|}{ 2-mal „Anatomie und } \\
\hline Biomechanik der Hand“" & Seite 32 \\
\hline Und außerdem & \\
\hline 2 TOGU Bodybones & Seite 26 \\
\hline
\end{tabular}

